\title{
Temporal changes in visual and acoustic codes in a letter-matching task
}

\author{
GARY THORSON, LARRY HOCHHAUS, and ROBERT F. STANNERS \\ Oklahoma State University, Stillwater, Oklahoma 74074
}

\begin{abstract}
The objective of the present experiment was to examine the nature of the coding process in a letter-matching task. Letter pairs that were either visually confusable or acoustically confusable or both visually and acoustically confusable were presented tachistoscopically with a variable interval between the first letter and the comparison letter. The dependent measure was RT for the "different" responses to the three types of confusable items which were each assessed at four interstimulus intervals ranging from 0 to $2 \mathrm{sec}$. The results indicate that a visual code appears to be emphasized for approximately $1 \mathrm{sec}$, after which an acoustic code seems to be dominant. There is also evidence which indicates that the acoustic code does not immediately replace the visual code and that both may coexist for a brief period of time.
\end{abstract}

The estimated duration of visual information appears to depend on the method used to obtain the estimate. In a recall task, Sperling (1960) used partial reports to infer that visual features decay in approximately $250 \mathrm{msec}$. Posner, Boies, Eichelman. and Taylor (1969), using a letter-matching task. extended the estimated range of visual information storage to approximately $1.000 \mathrm{msec}$. While it is very likely that the type of visual storage observed by Sperling (1960) is quite different from that type observed by Posner et al. (1969). both types of storage appear to be primarily visual and not acoustic in nature. Kroll. Parkinson, and Parks (1972), using a tree recall task combined with auditory shadowing. have estimated visual information is maintainable for as long as $20 \mathrm{sec}$. These results indicate that the subject may have a substantial amount of control over the duration of visual information.

Dainoff (1970) found that if two letter names were highly acoustically confusable according to the norms of Conrad (1964), the reaction time (RT) to judge the two letters as different increased as the interstimulus interval (ISI) increased. Dainoff interpreted the results as indicating an increasing likelihood of acoustic processing with increasing ISI and a concurrent decreasing likelihood of visual processing with increasing ISI. However, no appropriate data were offered which demonstrated a reduction in visual processing. One of the objectives of the present study was to determine whether visual confusability would operate in a manner analogous to acoustic confusability. According to Dainoff (1970), any effect of visual confusability should be manifested at shorter ISIs than acoustic confusability.

To test both of the major predictions of the Dainoff

This research was supported in part by funds from the Oklahoma State University Research Foundation. G. Thorson is now at the Department of Psychiatry and Behavioral Sciences. University of Oklahoma Health Sciences Center, P.O. Box 26901, Oklahoma City. Oklahoma 73190.
(1970) model, the present experiment employed letters for which visual and acoustic confusability were varied individually as well as conjointly. Such a procedure would also provide another independent estimate of the value found by Posner et al. (1969) for the time course of visual trace preference. In summary, the predictions concerning the three types of confusability were (a) that visual confusability should have the strongest effect on RT at relatively short $(0-1 \mathrm{sec})$ ISIs, (b) that acoustic confusability should be maximally disruptive at longer $(1-2 \mathrm{sec})$ ISIs, and (c) that conjoint confusability should operate at all ISI values.

\section{METHOD}

\section{Subjects}

The subjects were 16 volunteers ( 9 males and 7 females) from introductory psychology classes who received a small extra credit for participation. The subjects were right-handed and reported normal vision without the use of corrective lenses.

\section{Apparatus \\ A three-tield Scientific Prototype tachistoscope (Model GB) was used to present the materials. All three fields were maintained at a luminance of $2.0 \mathrm{fic}$ throughout the experiment. A voltage output from the control system of the tachistoscope was used to start a Hunter Klockounter at the onset of the second stimulus. The subject's response, via a toggle switch. stopped the clock-counter.}

\section{Materials}

Acoustic confusability was determined by Conrad's (1964) acoustic confusion matrix which gives the frequency of letter confusions in a listening task. This empirical matrix has been successfully used by Dainoff (1970) and Dainoff and Haber (1970) in a letter-matching task.

While there are confusion matrices based on visual materials, they were not employed in the present study. Fisher. Monty, and Glucksberg (1969) have pointed out the lack of agreement in the various matrices presently available and suggested that difference exposure durations, report techniques, and letter styles could be the cause of these discrepancies. Visual letter confusability in the present study was determined by the number of shared visual features according to the feature list of Gibson (1967).

The acoustic confusion condition (AC) consisted of eight pairs of letters with acoustic confusion values in Conrad's (1964) matrix 
ranging from 116 to 478 and two or fewer visual distinctive features in common according to Gibson (1967). The AC items were: A-O, E-D, E.P. F.S. F-X, N-A, P.Q. and X-S.

The items in the visual confusion condition (VC) consisted of eight letter pairs with three or four distinctive features (Gibson, 1967) in common and relatively low acoustic confusion values which ranged from 0 to 17 (Conrad, 1964). The VC items were: P-R, E-F, X-Y, $\mathrm{M} \cdot \mathrm{W}, \mathrm{T}-\mathrm{I}, \mathrm{Y}-\mathrm{V}, \mathrm{X} \cdot \mathrm{V}$, and $\mathrm{K} \cdot \mathrm{X}$.

The acoustic plus visual confusion condition $(A C+V C)$ items were: $\mathrm{M}-\mathrm{N},-\mathrm{K}-\mathrm{A}, \mathrm{E}-\mathrm{B}, \mathrm{T}-\mathrm{P}, \mathrm{B}-\mathrm{D}, \mathrm{T}-\mathrm{E}, \mathrm{B}-\mathrm{T}$, and B-P. The materials were prepared for presentation by pressing Para-Type No. 11315 uppercase letters on clear acetate and mounting in 35-mm slide holders.

\section{Procedure and Design}

Each subject was seated in front of the tachistoscope and asked to read the typed instructions. The instructions indicated that the subject was to respond on the basis of the name of the letter, as in Posner et al. (1969). At the beginning of each trial, the subject was shown a white field with two horizontal rows of block dots designating a fixation area. Each letter appeared in the same position. centered in the designated fixation field. With the warning ("Ready?") from the experimenter, the subject could then initiate the presentation series by using his thumb to press a button held in his nonpreferred hand. A single capital letter was tachistoscopically presented for a duration of $.5 \mathrm{sec}$ followed by the original white fixation field which reappeared for an ISI of $0 . .5 .1 .0$, or $2.0 \mathrm{sec}$. At the end of the ISI, the second letter appeared and the clock-counter started simultaneously. The subject then indicated whether the items had the "same" or a "different" name via a toggle switch. The left-right position of the switch was balanced between subjects, but was consistent within a single subject. Both RT and whether the response was correct or incorrect were recorded.

The variables of the experiment were type of confusion (AC, VC, and $A C+V C$ ) and $I S I$; both variables were manipulated within subjects. Each of the eight letter pairs for each type of confusion was presented twice at each of the four ISIs. Therefore, there were 16 RTs in each treatment combination for each subject. Additionally, each stimulus letter appeared twice at each ISI with the same letter repeated as the second letter to keep "same" and "different" responses at equal probabilities. The 384 test trials were randomly ordered for each subject separately and distributed over two sessions of approximately $60 \mathrm{~min}$ each. The first session was preceded by 30 practice trials, but no practice was given prior to the second session.

\section{RESULTS}

The overall error rate was very low $(.6 \%)$. Error trials were repeated at the end of the second session to provide an equal number of correct responses per subcondition.

A score for each subject was calculated by taking the geometric mean of the 16 RTs in a subcondition. The logarithmic transformation was used to reduce the influence of a relatively few atypical RTs. A plot of the subcondition means within ISIs is presented in Figure 1.

The results of a two-way analysis of variance are as follows: the effect of the interstimulus interval was significant, $F(3,45)=18.984, p<.001$. The RTs were fastest at the middle value of the ISI and slowest at very short and very long ISIs. The interaction of ISI and type of confusion was also significant, $F(6,90)=$ $20.403, p<.001$. The effect of type of interference (acoustic or visual) was very different at different ISIs (see Figure 1). At short ISIs, VC items produced

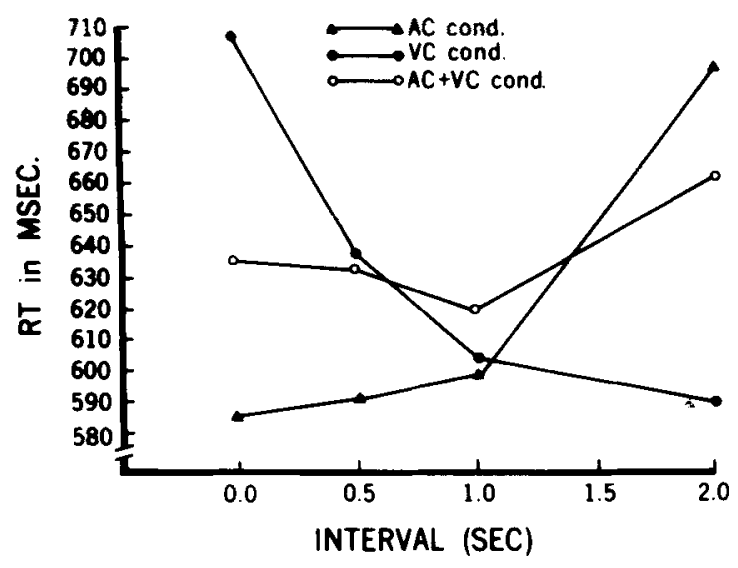

Figure 1. Mean RT to the three types of stimuli at the four ISIs.

longer RTs than AC items. At long ISIs, AC items produced longer RTs than VC items. The AC + VS items produced longer RTs than the $\mathrm{AC}$ items at short ISIs and longer RTs than the VC items at the 2.0-sec ISI. As a result of the canceling effect of $A C$ and $V C$ at different ISIs, the main effect of type of confusion was very small, $F(2,30)=3.258, p>.05$.

The HSD (Kirk, 1968) multiple comparisons test produced the following results: at the 0 -sec ISI, all two-condition comparisons among $\mathrm{AC}, \mathrm{VC}$, and $\mathrm{AC}+\mathrm{VC}$ were significant at the .01 level. At the .5 -sec ISI, the difference between the $\mathrm{AC}$ and $\mathrm{AC}+\mathrm{VC}$ conditions as well as the difference between the AC and VC condition were significant, $\mathrm{p}<.05$. At the 2.0-sec ISI, the difference between the $A C$ and $V C$ conditions and the difference between the $\mathrm{VC}$ and $\mathrm{AC}+\mathrm{VC}$ conditions were significant, $p<.01$. All other comparisons did not achieve the .05 level.

\section{DISCUSSION}

The hypothesis that visual confusability can increase the latency of matching responses at short ISIs was supported. The influence of visual confusability was still present at the .5-sec interval, which is well beyond the duration of the icon indicated by Sperling's (1960) method of partial report and indicates that under the conditions of the present experiment there is a maintenance of visual physical feature information for some time after the icon disappears. The substantial effect of confusability on RT provides empirical justification for defining confusability by physical feature overlap. This approach to defining visual confusability is consistent with the multicomponent model of letter recognition proposed by Rumelhart (Note 1).

The large increase in average RT to acoustically confusable items suppcrts the second hypothesis that acoustic confusability will interfere with "different" 
responses at longer ISIs. The fact that acoustically confusable items at $2 \mathrm{sec}$ required much more time for a "different" response than did the visually confusable items indicates that, by this time, the subject's comparison is largely based on an acoustic code. The AC $+V C$ condition produced relatively long average RTs at all ISIs. One apparent discrepancy from the predicted effect of $\mathrm{AC}+\mathrm{VC}$ occurred at the 0 -sec ISI, where the mean for VC was significantly greater than that for the $A C+V C$ condition. This result could be due to some differences in the distinctive feature overlap for the two conditions. The visual distinctive feature overlap for the $\mathrm{AC}+\mathrm{VC}$ condition was not as precise as that for the VC condition. Common position of shared distinctive features was a criterion for the VC condition, but due to the small number of letters which are both acoustically and visually confusable. the position criterion was not used in the $\mathrm{AC}+\mathrm{VC}$ condition.

A comparison of the $\mathrm{RT}$ functions under the $\mathrm{AC}$ and $\mathrm{VC}$ conditions suggests that the loss of the visual code and the development of the auditory code are not completely rigid processes. At the 1-sec ISI, the average RTs for both $A C$ and VC conditions are very similar and relatively low. But the explanations for the performance in the two conditions is essentially opposite. RT in the VC condition is low presumably because the subjects are using principally auditory information to make the comparison, while RT in the $\mathrm{AC}$ condition is low because the subjects are using principally visual information to make the comparisons. If these inferences are correct, then there must be some choice in the type of information used to make the comparison.

Another feature of the results suggests that there is some flexibility in the type of information used in the comparison. The AC function begins to rise sharply only atter a 1-sec delay, suggesting that the auditory code requires at least $1 \mathrm{sec}$ to develop. However, the average latency to the second letter at the $2-\mathrm{sec}$ interval. when the auditory code is presumably well established, is only $694 \mathrm{msec}$, which includes a substantial motor component. If the auditory code took at least a full second to develop for the first letter. then one would expect it to require a similar time for the second letter, and, yet, the RT is much less than 1 sec. A possible answer is that the auditory code is available much sooner than $1 \mathrm{sec}$, but the visual code continues to be the preferred basis of comparison up to at least $1 \mathrm{sec}$ for the AC materials.
Possibly, visual feature information extracted from the icon is easily maintained for $1 \mathrm{sec}$, but after this time the use of visual information requires regeneration. Therefore the auditory code would be a more efficient means of matching.

In summary, the results of the present study are generally consistent with the idea that the name code of a letter is extracted from its physical code. It does not appear, however, that the name code replaces the physical code immediately. Rather, the physical code and the name code are maintained simultaneously for a period of time. The suggestion of Posner and Warren (1972) that the characteristics of the subject and task demands will determine which code the subject will choose to emphasize and maintain seems to have been substantially supported in the present data.

\section{REFERENCE NOTE}

1. Rumelhart. D. E. A multicomponent theory of confusion among briefly exposed alphabetic characteristics. Center for Human Information Processing. La Jolla, California. Technical Report No. 22, 1971.

\section{REFERENCES}

CONRAD, R. Acoustic confusions in immediate memory. British Journal of Psychology. 1964, 55. 75-84.

Dainoff. $M$. T. Time course of visual and auditory encoding. Journal of Experimental Psychology, 1970, 86, 214-224.

Dainoff, M. T., \& HABER, R. M. Effect of acoustic confusability on levels of information processing. Canadian Joumal of Psychology, 1970, 24. 98-108.

Fisher. D. F.. Monty. R. A.. \& Glucksberg, S. Visual confusion matrices: Fact or artifact? Joumal of Psychology. 1969, 71, 111-125.

Gibson. E. T. Principles of perceptual learning and development. New York: Appleton-Century-Crofts. 1967.

KIRK. R. E. Experimental design procedures for the behavioral sciences. Belmont. Calit: Brooks/Cole, 1968.

Kroll, N. E. A., Parkinson. S. R.. \& Parks. T. E. Sensory and active storage of compound visual and auditory stimuli. Journal of Experimental Psychology. 1972, 95. 32-38.

Posner, M. I., Boies, S. T., Eichelman, W. H., \& Taylor, R. L. Retention of visual and name codes of single letters. Journal of Experimental Psychology Monograph. 1969. 79. 1-16.

Posner. M. I.. \& Warren, R. E. Traces. concepts, and conscious constructions. In A. W. Melton \& E. Martin (Eds.). Coding processing in human memory. New York: Wiley, 1972. Pp. 25-40.

SPERLing. G. The information available in brief visual presentations. Psychological Monographs, 1960. 74(11. Whole No. 498).

(Received for publication September 22, 1975; revision received January 16,1976 .) 